\title{
Interest-Rate Modeling Conundrums
}

\author{
Peter C. L. Lin 1,2 \\ ${ }^{1}$ Department of Mathematical Sciences, Financial Engineering Division, Stevens Institute of Technology, \\ Hoboken, USA \\ ${ }^{2}$ Gamma Paradigm Capital, New York, USA \\ Email: peter.lin@stevens.edu
}

Received 27 August 2014; revised 30 September 2014; accepted 11 October 2014

Copyright (C) 2014 by author and Scientific Research Publishing Inc.

This work is licensed under the Creative Commons Attribution International License (CC BY).

http://creativecommons.org/licenses/by/4.0/

c) (i) Open Access

\begin{abstract}
The mainstream research in interest-rate modeling has been focusing on a collection of risk tools and pricing formulas which are developed based on the simplified market assumptions and hypotheses. Despite the elegance of the structure, it is noticed that a crucial yet natural factor is missing: the relationship between curve-fitting algorithms and no-arbitrage restrictions on a bond portfolio. Also, the discrepancy between risk-free and default-free bonds is often ignored. This study discusses the modeling conundrums and proposes a framework based on the preferredhabitat hypothesis for advanced term-structure construction that overcomes these limitations in current models. This article serves as an introduction for future work.
\end{abstract}

\section{Keywords}

Interest-Rate Models, Preferred-Habitat Hypothesis, No-Arbitrage Conditions, Curve-Fitting Algorithms, Bond Portfolios

\section{Introduction}

The expectations hypothesis proposed by Fisher [1] assumes that zero-coupon bonds of different maturities are perfect substitutes. In general, equilibrium risk-free interest-rate models are based on the expectations hypothesis though the hypothesis comes in three forms:

$$
\text { Local Expectations Hypothesis }(\mathrm{LEH}): B_{r f}(t, s)=E\left[\exp \left(-\int_{t}^{s} R(v) \mathrm{d} v\right)\right]
$$

$$
\text { Return-to-Maturity Expectations Hypothesis (RME) : } B_{r f}(t, s)=\frac{1}{E\left[\exp \left(\int_{t}^{s} R(v) \mathrm{d} v\right)\right]}
$$




$$
\text { Unbiased Expectations Hypothesis }(\mathrm{UEH}): F_{r f}(0, s)=E[R(s)] \text {. }
$$

Here $B_{r f}(t, s)$ denotes the risk-free zero-coupon bond at time $t$ with maturity time $s$, and $F_{r f}(t, T)$ denotes risk-free instantaneous forward curve at time $t$ with term (time-to-maturity) $T$. Consequently, the short-rate process $R(t)$ is equivalent to $F_{r f}(t, 0)$. The expectation $E$ is taken under the real-world measure $\mathbb{P}$. Following from the arbitrage-free condition from Harrison and Pliska [2], the equality from (1) indicates a risk-neutral world where risk premium is zero, and the risk-neutral measure $\tilde{\mathbb{P}}$ and the real-world measure $\mathbb{P}$ coincide. The equality from (3) indicates a risk-neutral world where risk premium is zero when the numeraire is $B(\cdot, s)$ instead of a money market account ${ }^{1}$, and the forward risk-neutral measure $\tilde{\mathbb{P}}^{s}$ and the real-world measure $\tilde{\mathbb{P}}$ coincide.

The LEH and RME hypotheses are exclusive unless the short rate is deterministic. The LEH and UEH are exclusive when risk-free bonds are not tradable asset which is the asset with zero volatilities ${ }^{2}$. This study proposes a no-arbitrage framework that is consistent with the three expectations hypotheses. Then, based on the risk-free interest-rate modeling framework, default-free bonds ${ }^{3}$ are included to represent a form of tradable asset that is characterized in relation to risk-free bonds.

When buying and holding a default-free bond until its maturity, the return is risk-free, and the yield should equal to the risk-free return over the same investment horizon. Nonetheless, unlike risk-free bonds, default-free bonds are tradable and are affected by the supply and demand of the buyers and sellers. If we may borrow the term, convenience yield, from a commodity for representing the benefit of holding physical assets while quantifying supply-and-demand factor, the distinction between risk-free and default-free bonds can be described in the same fashion by introducing a term structure of "inconvenience yield" on the default-free bond. In accordance to the preferred-habitat hypothesis, this inconvenience is an analogy of the trading restrictions of arbitrages and the supply-and-demand factor of different maturity bonds.

The preferred-habitat hypothesis proposed by Culbertson [5] and Modigliani and Sutch [6] assumes that bonds of different maturities are close substitutes but not perfect. The hypothesis separates an interest-rate curve into two paradigms consisting of the expectations hypothesis and the market-segmentation hypothesis. As the expectations hypothesis states, this part of the curve is driven by arbitrageurs who take advantage of price discrepancy between bond with different maturities. On the other hand, the market-segmentation hypothesis asserts the existence of preferred-habitat investors who seek only bonds with specific maturities. Consequently, the preferred-habitat investors contribute the term-specific idiosyncratic risk and supply-and-demand effect. The aggregated effect from the market-segmentation hypothesis is called liquidity premium. This study proposes a new modeling framework based on the preferred-habitat hypothesis in which the liquidity premium is quantified endogenously and is linked to the inconvenience yield consistently under empirical practice between curve-fitting and bond portfolios.

A curve-fitting algorithm reduces the possible infinite-dimensional market model to a factor model with few sources of randomness. Sometimes the algorithm associated with a curve is pre-defined. For example, the High-Quality-Corporate Bond Yield curve proposed by US Treasury, which is used to discount the corporate pension liability, follows specific steps to construct. In other cases, industries pick the common algorithms like Nelson-Segal method or the quasi-cubic Hermite spline method for statistical or computational reasons. Nonetheless, fitted curve dynamics under the empirical measure usually admit arbitrages due to simplified assumption from the expectations hypothesis. In other words, if the market only follows an assumption without market segmentation, then the Heath-Jarrow-Morton framework restricts the curve factor loadings to be exponential splines. Detailed discussion can be found in Filipovic [7].

In order to resolve the no-arbitrage dynamics of a fitted curve, one shall examine the difference of a fitted curve and the bond portfolio the curve is fitted to. Based on the preferred-habitat hypothesis, term-specific idiosyncratic risk is added to a bond portfolio under the restriction that the idiosyncratic risk vanishes after applying a curve-fitting algorithm. Consequently, this more general framework will allow the use of any deterministic curve-fitting algorithm while guaranteeing the absent of arbitrages.

The interest-rate modeling conundrums then consist of three parts. First, a new no-arbitrage framework is needed to unify the expectations hypotheses under the preferred-habitat market assumption. Second, a connec-

\footnotetext{
${ }^{1}$ For the definition of numeraire and forward risk-neutral measure, please refer to [3].

${ }^{2}$ More detailed discussion can be found in Jarrow [4].

${ }^{3}$ The US Treasury bonds are often taken as proxy of default-free bonds.
} 
tion needs be established between any deterministic curve-fitting algorithm and no-arbitrage restrictions when incorporating the preferred-habitat market assumption. Third, it requires to provide a detailed implementation of an interest-rate model that satisfies the proposed framework. The last part is left for future study.

\section{A New Modeling Framework}

Recent research shows that no-arbitrage models do not capture supply and demand in the Treasury bond market. Krishnamurthy and Vissing-Jorgensen [8] showed that changes in Treasury supply have large effects on a variety of yield curve movements. Though their research focused on the spread between corporate and Treasury bonds, the result can be further applied to connect the money market account to the bond market. Furthermore, Duffee [9] exposed the idiosyncratic risk in short-term Treasury bills and postulated that this risk was the consequence of the time-variation of the inconvenience yield for holding Treasury bills. Concurrent research conducted by Duffie [10] showed similar idiosyncratic supply and demand for different maturities in the repo market. Moreover, we expect a similar result between deliverable Treasury bonds and Treasury bond futures. Here the cheapest-to-deliver option may affect bond market equilibrium through an imbalance of supply and demand in different maturities. In this section a new model framework is proposed by first focusing on the risk-free and default-free no-arbitrage model, then introducing the criteria for the no-arbitrage general term-structure models.

The gap between theoretical research in term-structure modeling and portfolio management is caused by the construction of the curves. In practice, a term structure is generally used to represent the market movements of a portfolio. For example, the US Treasury bond yield curve represents the portfolio consists of US Treasury bill, notes, and bonds. Many research have devoted to find the major factors in curve movement with respective to specific portfolios. When the portfolio is not dramatically variated, it is likely to identify few major components to characterize the portfolio. The technique is no different to a dimension reduction procedure. However, the model might be too simplified to capture any significant idiosyncratic risk. As a result, we propose a framework of a term-structure model by combining the conventional term-structure model paradigm and the random field.

Let $F$ denote the default-free instantaneous forward-rate curve representing a portfolio consists of defaultfree zero-coupon bonds $\{B(t, s)\}$ where $t, s$ are time and bond maturity respectively. Assume a bond dynamic is affected by the common factors and the term-specific idiosyncratic randomness that

$$
B(t, s)=\exp \left(-\int_{0}^{s-t} F(t, u) \mathrm{d} u+\eta(t, s-t) Z(t, s-t)\right)
$$

where $Z$ is a Brownian sheet with covariance structure $\eta$ and

$$
F(t, T)=G(t, T)+H(t, T)
$$

where $H(t, T)$ represents the term structure of liquidity premium of the default-free bond market with $H(t, 0)=0$ and $G(t, T)$ represents the equilibrium term structure of interest rate without market segmentation.

\section{Risk-Free vs Default-Free}

The first conundrum we shall discuss in fundamental term-structure modeling is to distinguish the risk-free and default-free curves. Though most literature treat the two curves indifferently with a reason that buying and holding a default-free asset creates a risk-free return, risk-free and default-free assets bear very different meanings since only the latter are tradeable. The HJM framework [11] provides a hint for improvement. First, by definition in [12], risk-free assets need to have zero volatility; hence it is necessary that $\eta \equiv 0$ for risk-free assets. Consequently, derived from the HJM framework, the volatility term of the risk-free curve needs to be (almost surely) zero at any time $t$ if assuming the interest-rate volatilities are non-negative. In addition, the liquidity premium and bond volatilities must be zero for all risk-free bonds because they are not marketable. Hence, for a risk-free curve, $H(t, T) \equiv 0$ and $G(t, T)=G(t, 0)$ for all $T$ since the forward risk-neutral measure coincides with conventional risk-neutral measure when bond volatilities are zero.

Consequently the HJM framework asserts that drift term of the curve process must also be zero. Hence we have the following no-arbitrage condition:

No-Arbitrage Condition 1. A risk-free curve $F_{r f}$ is almost surely constant with respect to time $t$, and

$$
F_{r f}(t, T)=G(t, T)=G(t, 0) \quad \forall T .
$$


Since $R(t)=F_{r f}(t, 0)$, from Condition 1 we have

$$
\tilde{\mathbb{E}}[R(t)]=\tilde{\mathbb{E}}^{t}[R(t)]=G(0, t) .
$$

Also, since the default probability approach zero when $T \rightarrow 0$, the default-free curve and the risk-free curve should agree on the point where $T=0$. Consequently the risk-free curve and short rate $R$ can be observed from a tradable market through the following constraint:

No-Arbitrage Condition 2. A default-free curve $F$ must satisfy that

$$
F(t, 0)=R(t)=F_{r f}(t, 0) .
$$

Unlike risk-free bonds, tradable default-free bonds are exempted from the zero-volatility constraint, yet the potential arbitrage might exist between buying-and-holding a default-free bond and a risk-free bond. Instead of applying an exogenous term structure of inconvenience yield to model the liquidity premium between two investments, we will quantify inconvenience yields endogenously based on a no-arbitrage condition between curve-fitting algorithms and bond portfolios. Let $\mathcal{A}$ denote an arbitrary deterministic curve-fitting algorithm. We claim that the expected future curve much be consistent with the curve fitted to the expected future bond portfolio:

No-Arbitrage Condition 3. Given a deterministic curve-fitting algorithm $\mathcal{A}$,

$$
\mathcal{A}\{\tilde{\mathbb{E}}[B(t, \cdot)]\}=\tilde{\mathbb{E}}[F(t, \cdot)] .
$$

Lemma 1. A sufficient condition for a default-free interest-rate curve satisfying No-Arbitrage Conditions 1-3 is

$$
\tilde{\mathbb{E}}[F(t, T)]=F(t, T), \quad \forall T .
$$

Proof. Given the default-free term structure and the diffusion term $\eta$, Condition 3 requires that the random field under a risk-neutral measure must yield

$$
\tilde{\mathbb{E}}[F(t, s-t)]=-\frac{\partial}{\partial s} \tilde{\mathbb{E}}\left[\exp \left(-\int_{0}^{s-t} F(t, u) \mathrm{d} u+\eta(t, s-t) \tilde{Z}(t, s-t)\right)\right]
$$

where $\eta(t, T)$ is non-zero. Therefore (10) implies

$$
\begin{aligned}
\tilde{\mathbb{E}}[B(t, s)] & =\tilde{\mathbb{E}}\left[\exp \left(-\int_{0}^{s-t} F(s, u) \mathrm{d} u+\eta(s, t-s) \tilde{Z}(s, t-s)\right)\right] \\
& =\exp \left(-\int_{0}^{s-t} \tilde{\mathbb{E}}[F(s, u) \mathrm{d} u] \mathrm{d} u\right)=\exp \left(-\int_{0}^{s-t} F(0, u) \mathrm{d} u\right)=B(0, s-t),
\end{aligned}
$$

which shows that the expected bond price with maturity $s$ at time $t$ is the same as the bond price with maturity $s-t$ at time 0 . Hence, bond yields with time-to-maturity $s-t$ remains the same for all $s \geq t$. It concludes that the fitted term structure of instantaneous default-free forward rate must be the same as the curve at time 0. Consequently the martingale property of the curve implies No-Arbitrage Conditions 1-3 given $H(t, 0)=0$ and $G=F_{r f}$ being flat.

Equation (9) is a natural extension from the bond-curve relationship in Equation (11). Hence, a term-structure model and its curve-fitting algorithm are unified. From Equations (11) and (12) and by rolling over ready-tomature default-free bonds we then have

$$
\tilde{\mathbb{E}}[B(t, s)]=\tilde{\mathbb{E}}\left[\exp \left(\int_{0}^{t} R(v)+\tilde{\mathbb{E}}[H(v, s-v)] \mathrm{d} v\right)\right]=\tilde{\mathbb{E}}\left[\exp \left(\int_{0}^{t} R(v)+H(0, s-v) \mathrm{d} v\right)\right]
$$

which shows that the liquidity premium implied by the default-free bonds represents a term structure of inconvenience yield. Hence, the no-arbitrage constraint between curve-fitting algorithms and bond portfolios is consistent with the preferred-habitat hypothesis from which term-specific spot inconvenience yields are computed endogenously.

\section{Conclusions}

In this study, a new no-arbitrage term-structure framework is proposed to overcome the no-arbitrage conun- 
drums in interest-rate modeling. Incorporating the preferred-habitat hypothesis with term-specific idiosyncratic risk associated with default-free bonds, a no-arbitrage connection between curve-fitting algorithms and bond portfolios is established. Then, the term structure of inconvenience yield is introduced and quantified endogenously to unify the risk-free and the default-free bonds. This framework further shows consistency between the supply-and-demand factor and the spot inconvenience yield and links back to traditional no-arbitrage paradigm.

This article serves as an introduction for future research. The next step will be implementing an interest-rate model that satisfies the proposed no-arbitrage conditions. Applications in either interest-rate forecasting or derivatives pricing can further test the robustness of the framework.

\section{References}

[1] Fisher, I. (1930) The Theory of Interest. Macmillan, New York.

[2] Harrison, J.M. and Pliska, S.R. (1981) Martingales and Stochastic Integrals in the Theory of Continuous Trading. Stochastic Processes and Their Applications, 11, 215-260. http://dx.doi.org/10.1016/0304-4149(81)90026-0

[3] Geman, H., El Karoui, N. and Rochet, J.-C. (1995) Changes of Numéraire, Changes of Probability Measure and Option Pricing. Journal of Applied Probability, 32, 443-458. http://dx.doi.org/10.2307/3215299

[4] Jarrow, R.A. (2009) The Term Structure of Interest Rates. Annual Review of Financial Economics, 2, 69-96. http://dx.doi.org/10.1146/annurev.financial.050808.114513

[5] Culbertson, J. (1957) The Term Structure of Interest Rates. Quarterly Journal of Economics, 71, 485-517. http://dx.doi.org/10.2307/1885708

[6] Modigliani, F. and Sutch, R. (1966) Innovations in Interest-Rate Policy. Interest-Rate Policy. American Economic Review, 56, 178-197.

[7] Filipovic, D. (2001) Consistency Problems for Heath-Jarrow-Morton Interest Rate Models. Springer, Berlin. http://dx.doi.org/10.1007/b76888

[8] Krishnamurthy, A. and Vissing-Jorgensen, A. (2010) The Aggregate Demand for Treasury Debt. Working Paper.

[9] Duffee, G.R. (1996) Idiosyncratic Variation of Treasury Bill Yields. Journal of Finance, 51, 527-551. http://dx.doi.org/10.1111/j.1540-6261.1996.tb02693.x

[10] Duffee, G.R. (1996) Special Repo Rates. Journal of Finance, 51, 493-526. http://dx.doi.org/10.1111/j.1540-6261.1996.tb02692.x

[11] Heath, D., Jarrow, R. and Morton, A. (1992) Bond Pricing and the Term Structure of Interest Rates: A New Methodology for Contingent Claims Valuation. Econometrica, 60, 77-105. http://dx.doi.org/10.2307/2951677

[12] Björk, T. (2009) Arbitrage Theory in Continuous Time. 3rd Edition, Oxford. 
Scientific Research Publishing (SCIRP) is one of the largest Open Access journal publishers. It is currently publishing more than 200 open access, online, peer-reviewed journals covering a wide range of academic disciplines. SCIRP serves the worldwide academic communities and contributes to the progress and application of science with its publication.

Other selected journals from SCIRP are listed as below. Submit your manuscript to us via either submit@scirp.org or Online Submission Portal.
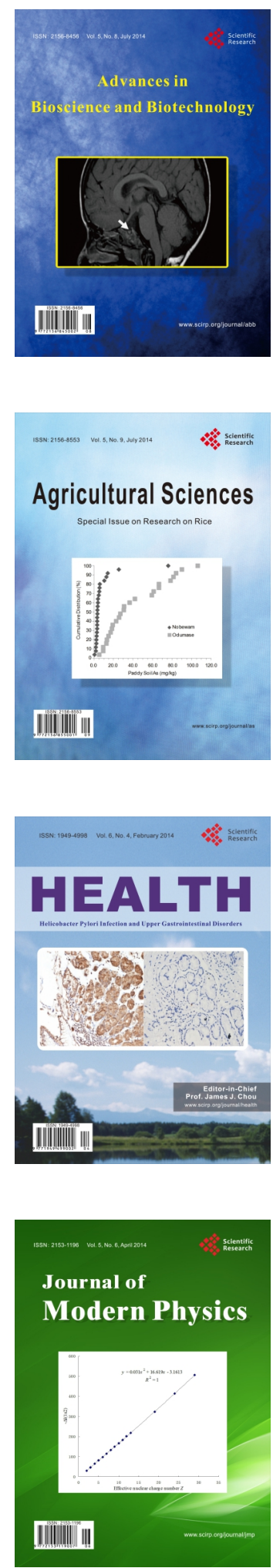
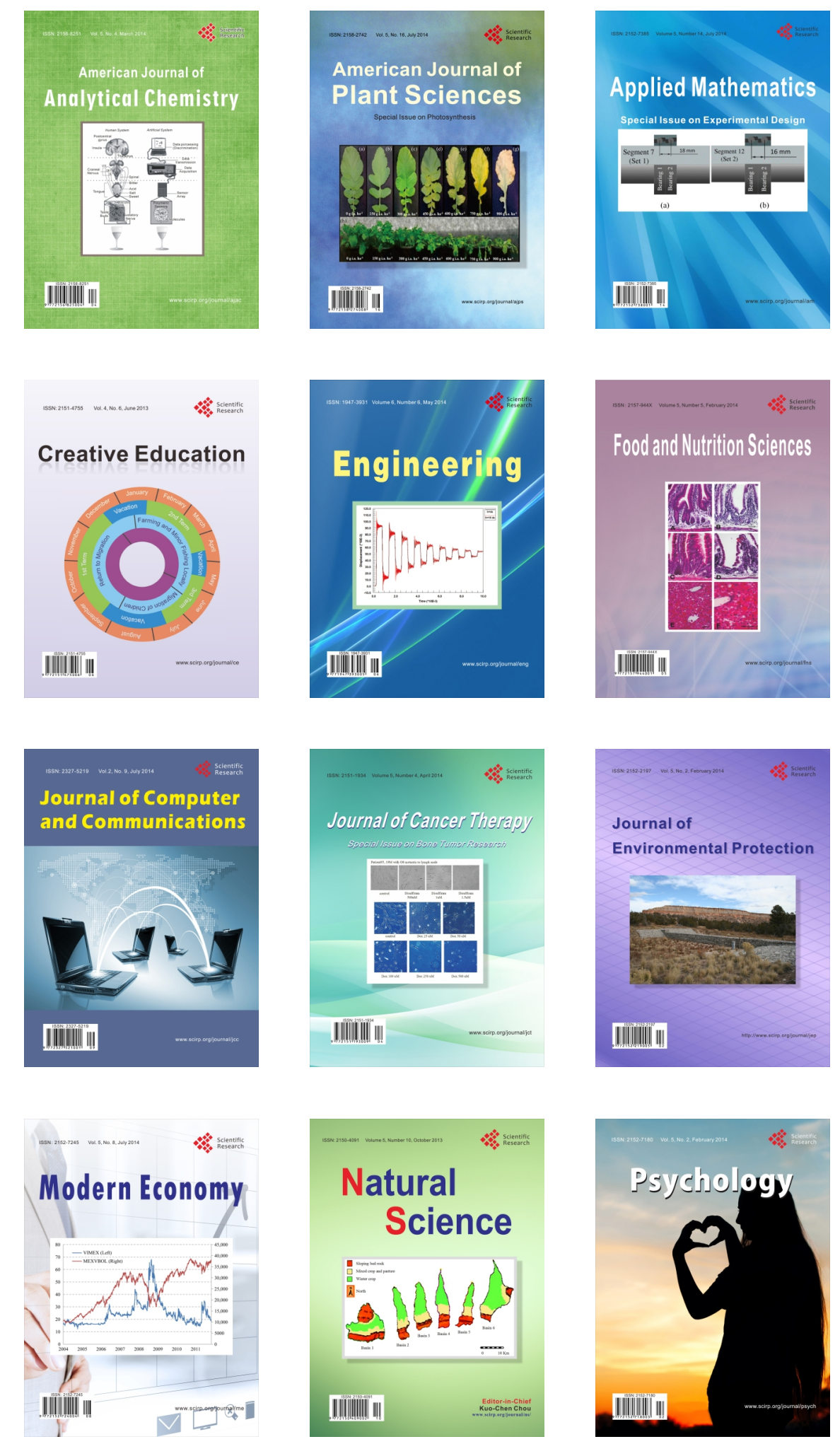